\title{
Synthesis of mesoporous carbon using gelatin as source of carbon by hard template technique and its characterizations
}

\author{
${ }^{1}$ Maria Ulfa ${ }^{*}{ }^{2}$ Wega Trisunaryanti, ${ }^{3}$ Iip Izul Falah, ${ }^{4}$ Indriana Kartini, ${ }^{5}$ Sutarno \\ 1,2,3,4,5 Department of Chemistry, Faculty of Mathematic and Natural Sciences, Gadjah Mada University, Jl \\ Sekip Utara 15, Yogyakarta 55720, Republic of Indonesia
}

\begin{abstract}
Synthesis of mesoporous carbon using gelatin as source of carbon by hard template technique (endotemplating) and its characterizations had been investigated. The mesoporous silica (SBA-15) as a template was reacted with the gelatie in a $\mathrm{H}_{2} \mathrm{SO}_{4}$ solution. The template-polymer composite was then pyrolyzed under a nitrogen flow at $900{ }^{\circ} \mathrm{C}$ for $3 \mathrm{~h}$ to carbonize the polymer and finished by silica removal from the composite using $\mathrm{NaOH}$ solution at temperature of $70{ }^{\circ} \mathrm{C}$ The properties of samples were characterized by $\mathrm{N}_{2}$ adsorptiondesorption isotherms, transmission electron microscopy (TEM), Fourier Transformation Infra Red Spectroscopy (FTIR), energy dispersive X-ray (EDAX) and Differential Thermal Analysis-Differential Scanning Calorimetry (DTA-DSC). The results showed that the ordered mesoporous carbon was obtained after dehydration, pyrolysis and silica removal process. The presence of nitrogen atoms in the gelatin as the precursors of carbon improved the thermal stability of the carbon. The mesoporous carbon sample have high content of carbon ( $85 \mathrm{wt. \% )}$ and thermal stabliity (up to $1400{ }^{\circ} \mathrm{C}$ ), specific surface areas of $580 \mathrm{~m}^{2} / \mathrm{g}$, total pore volumes of $0,5 \mathrm{~cm}^{3} / \mathrm{g}$, and pore diameter of $3,8 \mathrm{~nm}$.
\end{abstract}

Keywords: gelatin, mesoporous silica, endotemplating, thermal stability, pore diameter, mesoporous carbon

\section{Introduction}

The ordered mesoporous carbon have attracted special attention due to the unique character of properties such as porosity, chemical stability, heat resistance, electrical conductance and extensive applications of large molecules adsorption. Some carbon materials have been prepared by templating method using some organic compounds including polymers are employed as carbon precursors [1-3]. Polymers are a special group of compounds that possess promising and flexible features in this field. Their physical and chemical properties, for example, hydrophobic or hydrophilic character, thermal stability, and ability to form carbon, can be modified in a wide range, resulting in the formation of the most desirable product [4-6]. Many researcher have presented mesoporous carbons prepared by different types of precursor carbon [7-9]. There are also studies revealing the influence of carbon precursors on the chemical properties of the obtained porous carbons.

Gelatin is one of the polymer which possess lots of amino $\left(-\mathrm{NH}_{2}\right)$ functional groups can have a high affinity to strongly interact with silanol groups $(\mathrm{Si}-\mathrm{OH})$ on the silicate species via multiple hydrogen bonds [1011]. Gelatin is the potential of new precursor carbon due to the high carbon composition (up to $50 \mathrm{wt} \%$ ). The previous researcher used gelatin as precursor carbon and soft template by surfactant-templating method [12-13]. However, the obtained carbon materials in this previous work had poor textural parameters and porous structure because of low stability of gelatin micelle due to the low acidity, moisture and temperature.

Endotemplating strategy is one of the most popular techniques used for the preparation of mesoporous carbons [14-16]. This method was performed using mesoporous silica material as a hard template then impregnated with a carbon precursor material followed by pyrolysis, carbonization, and template removal. This method provided better thermal stability of the carbon.

Based on the above consideration, the authors undertaken synthesis and characterization of mesoporous carbon using the endotemplating method. The mesoporous silica (SBA-15) was used as a template and gelatin extacted from cow bones was prepared as carbon precursor. The properties of the product were investigated by $\mathrm{N}_{2}$ adsorption-desorption isotherms (Brunauer-Emmett-Teller, BET technique), transmission electron microscopy (TEM), Fourier transform infrared (FTIR) spectroscopy, energy dispersive X-ray (EDAX), thermogravimetric analysis (TGA) and differential scanning calorimetry ( DSC).

\subsection{Gelatin extraction}

\section{Experimental section}

Gelatin extracted from Javanese cow bone. The pretreated cow bones were mixed into acid then base water (at a ratio of $1 / 5, \mathrm{w} / \mathrm{v}$ ) for $1 \mathrm{~h}$ on two step then mixed with distiled water (at a ratio of $1 / 3, \mathrm{w} / \mathrm{v}$ ) and gelatin was extracted at $50{ }^{\circ} \mathrm{C}$ for $4 \mathrm{~h}$ using a Extracted gelatin was filtered using a Whatman 42 filter paper (Whatman, Maidenstone, England). Gelatin was then evaporated under vacuum at $50{ }^{\circ} \mathrm{C}$ using a Büchi 
Rotavapor model R-210 (Büchi UK Ltd., Oldham, UK). The specimen dried on freeze dried (Labconco Corporation, Kansas City, MO, USA) followed by grinded in 100 mesh.

\subsection{Preparation of mesoporous carbons}

Mesoporous carbon material was synthesized by using SBA-15 mesoporous material as a silica template (particle size $0,1 \mu \mathrm{m}$, pore diameter $7-8 \mathrm{~nm}$, surface area $550 \mathrm{~m}^{2} / \mathrm{g}$, pore volume $1,0 \mathrm{~cm}^{3} / \mathrm{g}$ ) and gelatin as the carbon source. In a typical synthesis of mesoporous carbon, $1 \mathrm{~g}$ of template (mesoporous silica material)

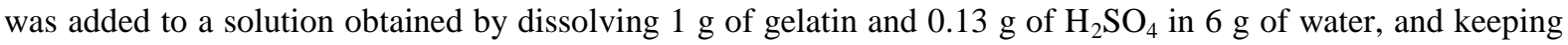
the mixture in an oven for $7 \mathrm{~h}$ at $110{ }^{\circ} \mathrm{C}$. Subsequently, the oven temperature was raised to $150{ }^{\circ} \mathrm{C}$ for $7 \mathrm{~h}$. In order to obtain fully polymerized and carbonized gelatin inside the pores of the silica template, $0,5 \mathrm{~g}$ of gelatin, $0.11 \mathrm{~g}$ of $\mathrm{H}_{2} \mathrm{SO}_{4}$ and $5 \mathrm{~g}$ of water were again added to the pre-treated sample and the mixture was subjected to the thermal treatment described above. The template-polymer composites were then pyrolyzed in a nitrogen flow at $900{ }^{\circ} \mathrm{C}$ and kept under these conditions for $3 \mathrm{~h}$ to carbonize the polymer. The mesoporous carbon was recovered after dissolution of the silica framework in $\mathrm{NaOH} 2 \mathrm{M}$ at temperature of $70^{\circ} \mathrm{C}$, by filtration, washed several times with ethanol, and dried at $120{ }^{\circ} \mathrm{C}$ produced the mesoporous carbon of gelatin sample. A set of samples prepared at different step during the synthesis were labeled as follows: Ge for gelatin, Ge-S1 for the gelatin-silica composite before pyrolysis, Ge-S2 for the gelatin-silica composite after pyrolysis and MCG represented a mesoporous carbon of gelatin.

\subsection{Characterization}

Elemental analysis of sample was obtained on Energy Dispersive X-ray (EDAX) (Genesis). System of EDAX permits submicrometer elemental identification and compositional analysis. Samples of EDAX were prepared by depositing particles from an alcohol suspension on carbon covered nickel grids. Fourier transform infrared (FTIR) spectra were obtained on a Bruker FTIR spectrophotometer Shimadzu. Nitrogen adsorption and desorption isotherms were measured on a Quantachrome Autosorb 1 sorption analyzer. All samples were outgassed at $300{ }^{\circ} \mathrm{C}$ for $3 \mathrm{~h}$ prior to the nitrogen adsorption measurements. The specific surface area was calculated using the Brunauer-Emmett- Teller (BET) method. The pore size distributions were obtained from the adsorption branch of the nitrogen isotherms by Barrett-Joyner-Halenda method. Thermogravimetric (TGA) measurements were carried out using a Netzsch derivatograph STA 449 F1 Jupiter (Netzsch, Germany) in the range from 25 to $1400{ }^{\circ} \mathrm{C}$ at a heating rate of $5{ }^{\circ} \mathrm{C} / \mathrm{min}$. The measurements were carried out in an open $\mathrm{Al}_{2} \mathrm{O}_{3}$ crucible under a helium or a synthetic air atmosphere at a flow rate of $40 \mathrm{~mL} \mathrm{~min}^{-1}$. An empty, open crucible was used as a reference. Differential scanning calorimetry (DSC) analyses were carried out on a Netzsch DSC 204 calorimeter (Netzsch, Germany). Samples of about $6 \mathrm{mg}$ weight were placed in an aluminum pan with a pierced lid, placed in a DSC oven, and heated from 25 to $1400{ }^{\circ} \mathrm{C}$ at a heating rate of $5^{\circ} \mathrm{C} / \mathrm{min}$. The measurements were conducted under a nitrogen atmosphere. An empty pan was used as a reference. The morphologies of all the synthesized samples were characterized by a transmission electron microscopy (TEM) instrument (Philips CM30) operating at $120 \mathrm{kV}$. Each sample was dispersed in absolute ethanol and a drop was placed on a $\mathrm{Cu}$ grid covered with perforated carbon film.

\section{Result And Discussion}

The results of elemental analyses of Ge, Ge-S1, Ge-S2 and MCG by EDAX Showed in Fig.1. The EDAX technique on this work can provide the effective atomic concentration of different substrates of investigated solids, for example, Ge which are present on their top surface layers high content of carbon in as an organic sample suggests its hydrophobicity, whereas a high content of other elements (especially nitrogen, silica, or oxygen that are often derived from functional groups) is responsible for the hydrophilic character of gelatin (Table 1). The results elemental analyses of formation mechanisms of mesoporous carbon are presented in Table 1.

Table 1. Elemental contents (mass \%) of samples

\begin{tabular}{lccccc}
\hline Sampel & $\mathrm{C}$ & $\mathrm{O}$ & $\mathrm{N}$ & $\mathrm{Si}$ & Others \\
\hline Ge & 47.98 & 29.44 & 14.42 & 0.00 & 8,16 \\
Ge-S1 & 18.51 & 41.14 & 8.01 & 22.50 & 17,85 \\
Ge-S2 & 21.06 & 50.20 & 0.00 & 28.73 & 0.01 \\
MCG & 85,84 & 14.16 & 0.00 & 0.00 & 0.00 \\
\hline
\end{tabular}



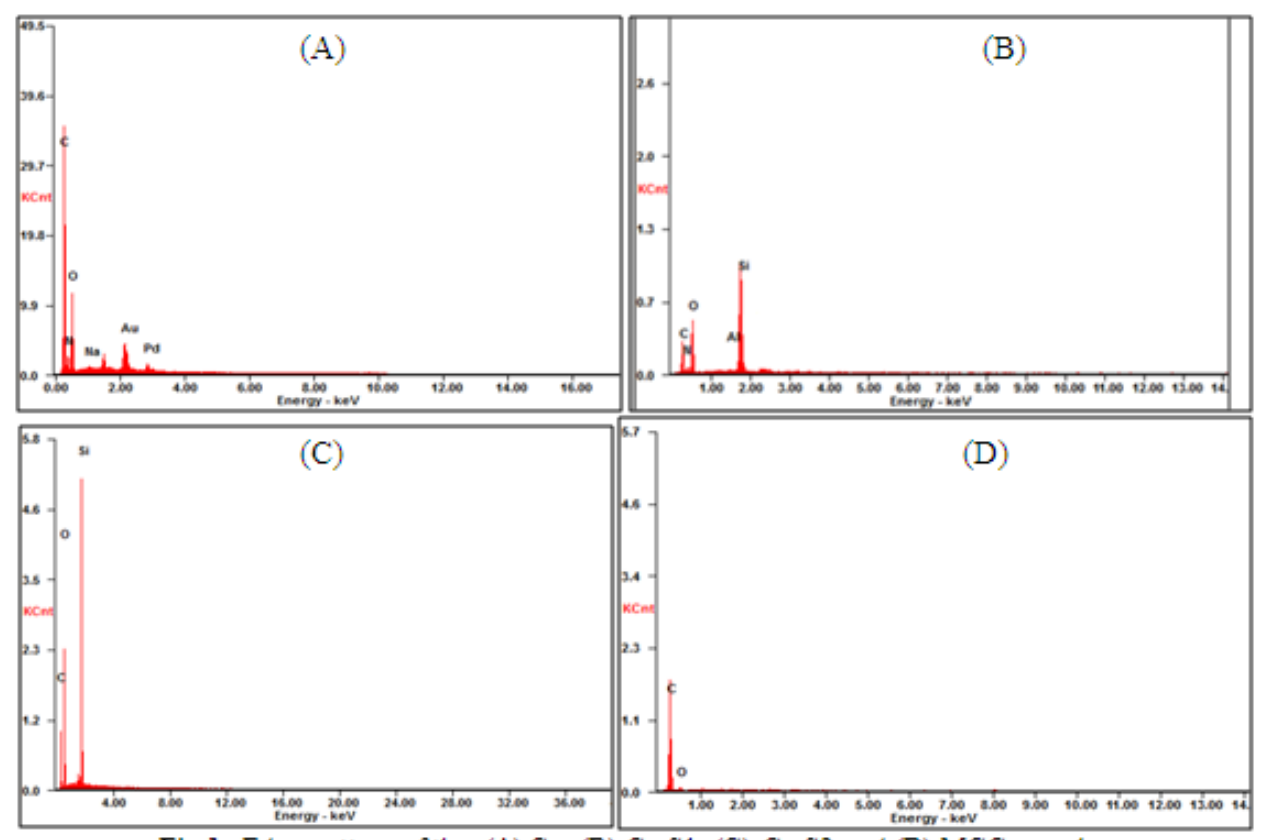

Fig.l Edax pattern of the: (A) Ge, (B) Ge-S1, (C) Ge-S2 and (D) MCG samples

The Ge-S1 prepared from gelatin and SBA-15 followed by dehydration step at $100-160{ }^{\circ} \mathrm{C}$ contain about $18,5 \%$ of carbon (Tabel 1). For this samples, the $\mathrm{N}$ and Si contents were high, owing to the fact that amine group interact with silika of SBA-15 by hydrogen bonding during infiltration process. Tabel 1 showed that Ge$\mathrm{S} 1$ sample contents consisted of $\mathrm{C}, \mathrm{N}, \mathrm{Si}, \mathrm{O}$ and other elements indicated a relatively small amount of functional groups present on the surface and showed some interaction between gelatin and SBA-15 using amine group and silika species via hydrogen bonding interaction. This interaction held on infiltration process and disappears on pyrolisis process as show in Ge-S2 sample due to the high temperature process. The elemental composition on the Ge-S2 sample was significantly affected by the carbonization process. The loss of $\mathrm{N}$ and increase of $\mathrm{C}$ content on the Ge-S2 sample showed that during carbonization process all nitrogen atom could be removed from the structure and converted gelatin molecule to the carbon. It revealed that the highest content of carbon $(85,84$ $\%$ ) was observed in the porous carbon samples. The MCG sample consisted only $\mathrm{C}$ and $\mathrm{O}$ element. This sample was carbonized at $900{ }^{\circ} \mathrm{C}$ then dissolution with $\mathrm{NaOH}$ produced pure carbon with oxygen on the surface due to the full conversion of gelatin molecule to carbon element.



Fig. 2 FT-IR spectra of the: (A) Ge), (B) GE-S1, (C) SBA-15 and (D) MCG samples

The differences in the surface functional groups were confirmed by FTIR analyses. The most intensive bands that were observed in Fig. 2 were derived from surface functional groups containing oxygen. The spectral of gelatin showed the band of changes in collagen secondary structure to gelatin with amine bonds in gelatin structure of the amide A $\left(3600-3200 \mathrm{~cm}^{-1}\right)$, amide I $\left(1636-1661 \mathrm{~cm}^{-1}\right)$, amide II $\left(1549-1558 \mathrm{~cm}^{-1}\right)$ and the amide III (1200-1300 $\left.\mathrm{cm}^{-1}\right)$ regions [17-18]. The spectral of the Ge-S1 sample showed the characteristic of SiO-Si stretching/bending absorbance at 461, 795, and $1080 \mathrm{~cm}^{-1}$ and the $\mathrm{Si}-\mathrm{OH}$ stretching absorbance at $960 \mathrm{~cm}^{-}$ 
1. The presence of 2922 and $2850 \mathrm{~cm}^{-1}$ absorbance peaks in the Ge-S1 sample corresponding to the stretching band of the $-\mathrm{CH}_{2}$ alkyl chain from the alkyl amine, indicated that gelatin was indeed introduced into the silica matrix as the precursor. The peaks at 1566 and $1398 \mathrm{~cm}^{-1}$ can be attributed to the $\mathrm{C}-\mathrm{O}$ stretching band of amino acid and carboxylate, respectively which confirmed the presence of gelatin in the silica matrix.
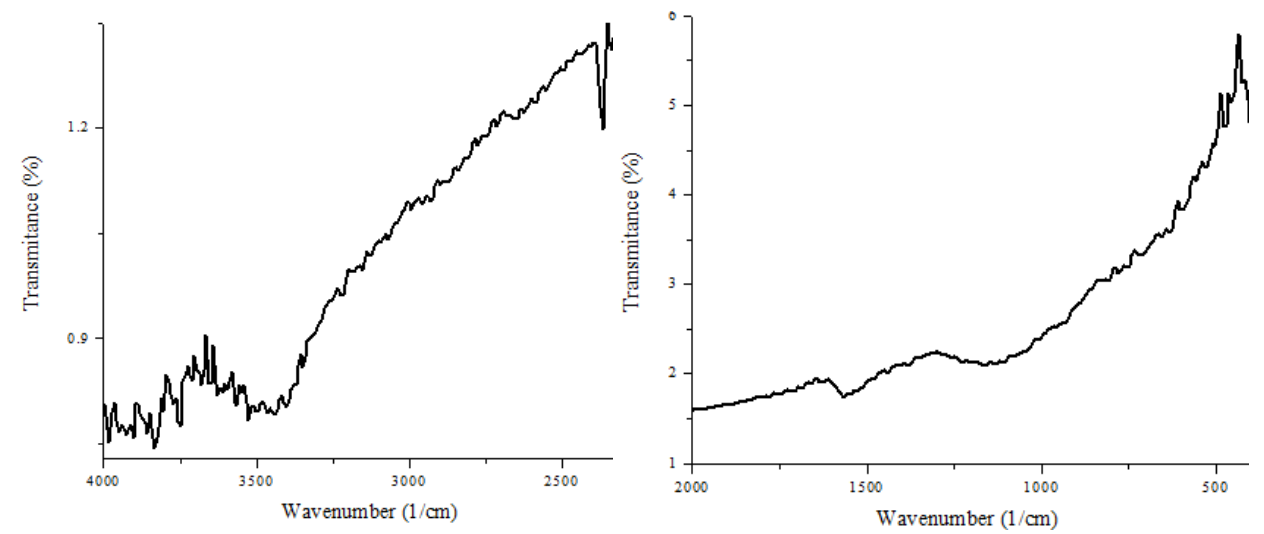

Fig. 3. FT-IR spectra of MCG sample at different wave number range

A large extension of the band of porous carbon MCG not only indicated the presence of numerous hydrogen bonds but can also be caused by the water adsorbed on the surface of the composite $\left(3600-3100 \mathrm{~cm}^{-1}\right)$ (Fig 3). The band in the range of $1300-1000 \mathrm{~cm}^{-1}$ was derived from the stretching vibrations of the C-O bonds presented in the following functional groups: anhydride $\left(980-1300 \mathrm{~cm}^{-1}\right)$, esteric $\left(1310-1250 \mathrm{~cm}^{-1}\right.$ and $1150-1080$ $\left.\mathrm{cm}^{-1}\right)$, lactonic (1160-1370 $\left.\mathrm{cm}^{-1}\right)$, alcoholic (1280-1050 cm-1), phenolic (1220-1000 $\left.\mathrm{cm}^{-1}\right)$, and etheric (1300-1 $\left.000 \mathrm{~cm}^{-1}\right)$. The region of 2000-1500 $\mathrm{cm}^{-1}$ was characteristic for double-bond vibrations [11,12]. In this region, the vibrations of $\mathrm{C}=\mathrm{C}\left(1680-1620 \mathrm{~cm}^{-1}\right)$, aromatic rings $\left(1600-1585 \mathrm{~cm}^{-1}\right), \mathrm{C}=\mathrm{O}$ from carboxylic $(1760-1665$ cm-1), carbonyl (1600-1590 cm-1), quinonic (1680-1550 cm-1), lactonic groups $\left(1790-1675 \mathrm{~cm}^{-1}\right)$, and anhydrides (1880-1740 cm-1) can be observed. Vibrations of the $\mathrm{CH}_{3}$ and $\mathrm{CH}_{2}$ groups are in the range of 3000$2800 \mathrm{~cm}-1$.The bands at $461,795,1080$, and $2850 \mathrm{~cm}^{-1}$ on the spectral of mesoporous carbon from gelatin MCG have disappeared, indicated that silica and alkyl amine can be completely removed by the $\mathrm{NaOH}$-ethanol extraction.

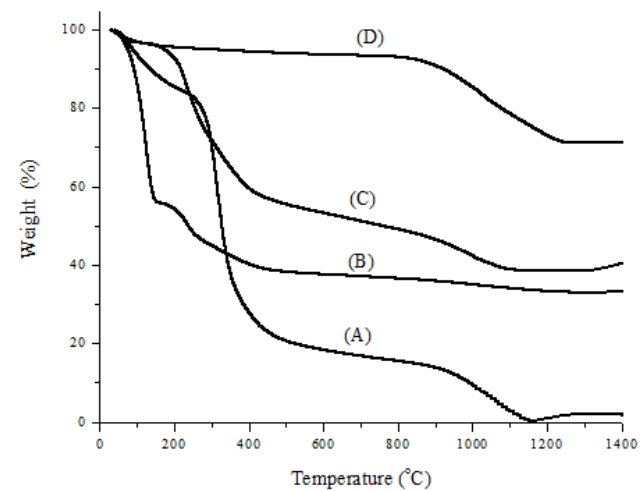

Fig. 4. The TGA curves of the (A) Ge, (B) Ge-S1, (C) Ge-S2 and (D) MCG sample

TG curves which characterized the thermal decomposition of Ge, Ge-S1, Ge-S2 and MCG are presented in Fig. 4. Table 2 showed the mass loss obtained by termogravimetry of the samples. In the case of the gelatin the mass loss occured in three stages: the first refered to the loss of structural water of the gelatin (20$\left.250{ }^{\circ} \mathrm{C}\right)$; the second refered to the thermal degradation of the polymeric chains of gelatin $\left(250-420{ }^{\circ} \mathrm{C}\right)$, the third (420-900 $\left.{ }^{\circ} \mathrm{C}\right)$ refered to the first carbonization of polymeric materials, the fourth $\left(900-1400{ }^{\circ} \mathrm{C}\right)$, to the last carbonization step of materials as the indicator of the thermal stability sample of material.

Table 2. Weight loss of gelatin, the composite of gelatin-SBA-15 and MCG

\begin{tabular}{crrrr}
\hline Sample & \multicolumn{4}{c}{ Weight \% } \\
\cline { 2 - 5 } & $20-250{ }^{\circ} \mathrm{C}$ & $250-420{ }^{\circ} \mathrm{C}$ & $420-900{ }^{\circ} \mathrm{C}$ & $900-1400{ }^{\circ} \mathrm{C}$ \\
\hline Ge & 17.3 & 55.7 & 15.5 & 0.0 \\
Ge-S1 & 41.1 & 17.2 & 1.7 & 40.0 \\
Ge-S2 & 4,7 & 30.1 & 15.1 & 50.1 \\
MCG & 4.3 & 0.1 & 0.1 & 79.8 \\
\hline
\end{tabular}


In the Ge-S1 sample, it was verified that two thermal degradation stage occured, one in the $25-190{ }^{\circ} \mathrm{C}$ range refers to loss of structural water of gelatin and the other at $190-225^{\circ} \mathrm{C}$, attributed to the gelatin and SBA15 structural degradation. In the correlation to the pure material temperature shift was observed in both Ge-S1 and Ge-S2 samples, suggested an interaction between gelatin and SBA-15. the TGA results showed a possible interaction involving the amine group of gelatin $\left(\mathrm{NH}_{2}\right.$ ) and mesoporous silica $\mathrm{SBA}-15$ groups ( $\mathrm{Si}-\mathrm{O}-\mathrm{Si}$ or $\mathrm{Si}$ $\mathrm{OH})$ and/or a hydrogen-bonding type as described by Hsu [19-20]. This interaction increases the thermal stability of the composite structures, gelatin and SBA-15. The weight of gelatin at $1160-1200{ }^{\circ} \mathrm{C}$ is zero refered to the low thermal stability, the other side, at the same temperature the Ge-S1 and Ge-S2 still have weight about 40 and $60 \%$ respectively. This result indicated that interaction between the amine group of gelatin $\left(-\mathrm{NH}_{2}{ }^{-}\right)$and mesoporous silica SBA-15 groups increased stability of the composite structure in high temperature. The MCG sample still have weight about $78 \%$ at high temperature $\left(1200-1400{ }^{\circ} \mathrm{C}\right)$ refered to the high thermal stability of material. Among all of the samples, mesoporous carbon of gelatin MCG was the sample which have highest thermal stability due to the regular pore of carbon, large shape and size pore and original performa of pore mesocarbon from gelatin.

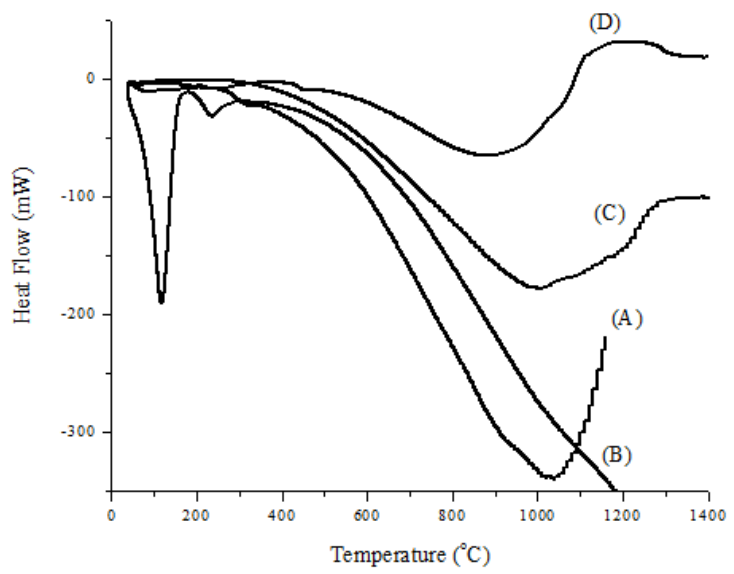

Fig.5 DSC curves of the (A) Ge, (B) Ge-S1, (C) Ge-S2 and MCG samples under $\mathrm{N}_{2}$ atmosphere

The DSC curve for all samples (Fig. 5) showed characteristic endothermic transitions of structural changes of the material related to the energy during process. It was found from DSC curve that triple helix of gelatin structural was changed due to the protein denaturation at 20-190 ${ }^{\circ} \mathrm{C}$. Gelatin need highest energy during conversion process to be the elemen of carbon. It was found that the energy consumption of the Ge-S1 was higher than that of Ge-S2. This phenomena due to a lot of functional group of the composite (amine, carboxyl, alkyl). The DSC curve showed that mesoporous carbon have smallest endothermic characteristic than other sample due to the high stability of material.

Table 3. Transisition temperature and heat flow of sample obtained from DSC

\begin{tabular}{lccc}
\hline Sample & \multicolumn{3}{c}{ Heat Flow $(\mathrm{mW} / \mathrm{g})$} \\
\cline { 2 - 4 } & $190{ }^{\circ} \mathrm{C}$ & $400-1000{ }^{\circ} \mathrm{C}$ & $1000-1400^{\circ} \mathrm{C}$ \\
\cline { 2 - 4 } Ge & -200 & -25 & -355 \\
Ge-S1 & 0 & 0 & $<<-350$ \\
Ge-S2 & 0 & -160 & -90 \\
MCG & 0 & -50 & +50 \\
\hline
\end{tabular}

Table 3 showed transition temperatures of sample structure obtained from DSC data. It was not possible to observe the transition for gelatin-SBA-15 due to the low intensity of the signal. Considering that three transition structural have been showed in the DSC curve of gelatin sample, it can be verified that a lot of functional group in the gelatin molecule (carboxylic, amine, alkyl) was changed to alkaline due to temperature increase. The integrity of the triple helix structure was preserved in gelatin sample, since denatured gelatin did not present any thermal transition in the temperature intervals studied [21-23]. The SBA-15 addition reduced transition temperature of the composite. This reduction occurred may be due to an influence of silica species of SBA-15 in the electrostatic interactions inside the gelatin structure. The regular pore carbon of MCG sample was changed at small energy due to the high thermal stability of material. 


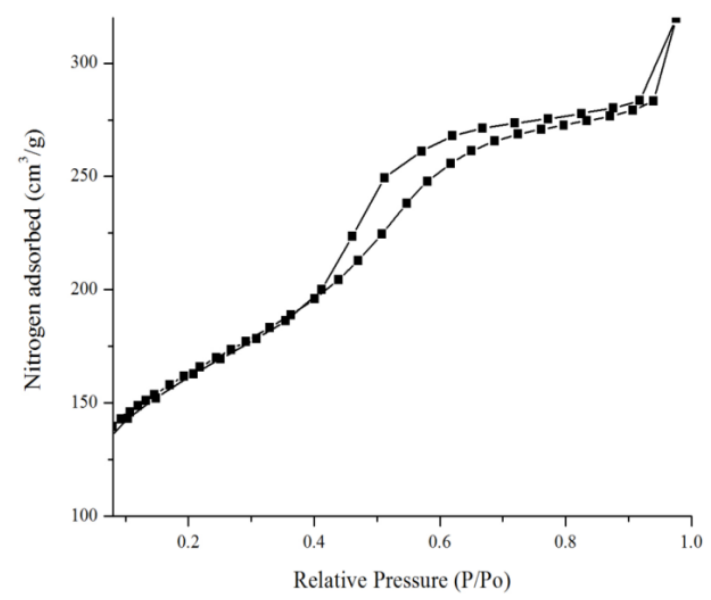

Fig. 6 Nitrogen adsorption-desorption isotherms of the MCG sample

The isotherm and pore size distribution (PSD) of MCG sample showed a porous structure with surface area $580 \mathrm{~m}^{2} / \mathrm{g}$, narrow PSD at pore diameter $3,7 \mathrm{~nm}$ was observed (Fig 6 and 7). As the relative pressure increases ( $\mathrm{p} / \mathrm{p} 0>0.35)$, the isotherms for MCG exhibit a sharp step characteristic of capillary condensation of nitrogen within uniform mesopores, where the $\mathrm{p} / \mathrm{p}_{\mathrm{o}}$ position of the inflection point is correlated to the diameter of the mesopore [24-26]. The large specific surface area could be attributed to the surface homogenity of mesoporous material because of the filling of gelatin molecules in the pore channels.

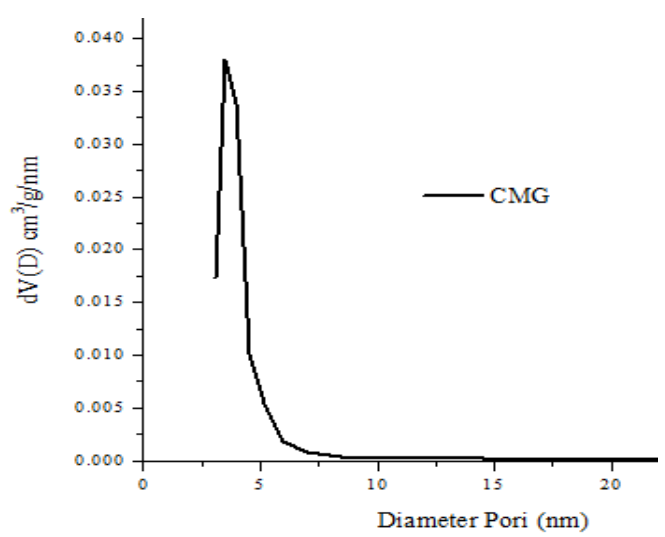

Fig. 7. BJH adsorption pore size distribution of mesoporous carbons from gelatin (MCG)

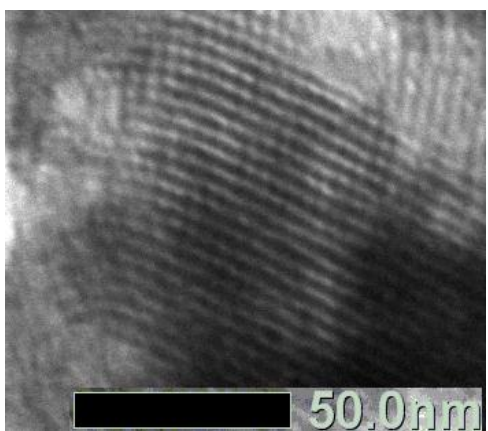

A

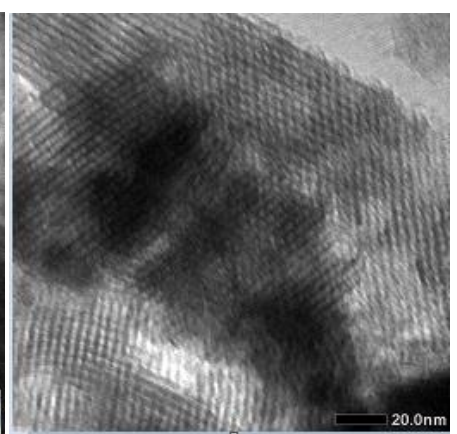

B

Fig. 8 TEM images of mesoporous carbon (MCG) (A) Channel direction (B) Perpendicular direction

Transmission electron microscope (TEM) was used to examine the morphology , the structural order and the microscopic feature of the materials mesoporous carbon from gelatin. Mesoporous carbon prepared from gelatin (MCG) showed mesoporous channels with an ordered mesoporous structure with linear array of mesopores, originating from the mesoporous silica framework that would convert into the mesopores of the resultant carbon after the $\mathrm{NaOH}$ treatment (Fig.8) The above results were consistent with the results and the conclusion derived from the $\mathrm{N}_{2}$ adsorption-desorption isotherms of those samples. 


\section{Conclusions}

Mesoporous carbon gelatin (MCG) have been synthesis by endotemplating methode using mesoporous silica SBA-15 as a template and gelatin as a carbon source. The MCG sample have mesoporous and physical properties such specific surface areas $580 \mathrm{~m}^{2} / \mathrm{g}$, total pore volumes $0,5 \mathrm{~cm}^{3} / \mathrm{g}$, pore diameter 3,8 , content of carbon about $85 \%$ and thermal stability up to $1400^{\circ} \mathrm{C}$. The mechanism of synthesis, pore structure and the textural parameters of the mesoporous carbon materials have been systematically investigated. Mesoporous silica addition results in interactions involving the amine groups of gelatin and silanol groups of SBA-15 by a hydrogen-bonding type detectable by FT-IR, DSC and TG/DTA. This interaction increase thermal stability of composite of both structures.

\section{Acknowledgement}

The financial support from the Indonesian Ministry of Education through the Hibah Unggulan Perguruan Tinggi Universitas Gadjah Mada 2014 Program (Contract Number: LPPM-UGM/384/LIT/2014) was gratefully acknowledged.

\section{References}

[1] K. Laszlo, A. Bota, L.G. Nagy, Comparative adsorption study on carbons from 1965-1976 polimer precursors, Carbon, 2000, 38-44

[2] Y.N. Sazanov, V. Gribanov, Cocarbonization of polymers as a new concept for synthesis of carbon composites, Russian Journal of Applied Chemistry, 79(3), 2006, 433-438.

[3] M. Blazso. Recent trends in analytical and applied pyrolysis of polymers, Jounal of Analysis and Applied Pyrolysis, 39(1), 1997, 125.

[4] S. Yenisoy-Karakas, A. Aygun, M. Gunes, Physical and chemical characteristics of polymer-based spherical activated carbon and its ability to absorb organics, Carbon, 42(4), 2004, 477-484.

[5] Z. Wang, Z. Lu, X. Huang, Chemical and cristalline structure characterizations of polyfurfuryl alcohol pyrolized at $600{ }^{\circ} \mathrm{C}$, Carbon, 36, 1998, 51-59.

[6] B. Gawdzik and M. Sobiesiak, Chemical composition of plasma treated polyimide microspheres, Applied Surface Science, 2003, 214

[7] T. Zhi-hong, H.Yan, E. Song, L.I. U. Lang, G. U. O. Quan-gui, Properties of mesoporous carbons prepared from different carbon precursors using nanosize silica as a template, New Carbon Materials, 25(6), 2010, 465-469.

[8] K. Bo, W. Einicke, O. Klepel, 2005. Templated synthesis of mesoporous carbon from sucrose - the way from the silica pore filling to the carbon material. Carbon , 43, 2005, 1918-1925.

[9] M Ignat, C.J.Van Oers, J.Vernimmen, M.Mertens, S.Potgieter-Vermaak, V.Meynen, E.Popovici,P.Cool, Textural property tuning of ordered mesoporous carbon obtained by glycerol conversion using SBA-15 silica as template. Carbon, 48(5), 2010, $1609-1618$.

[10] T. Coradin, S. Bah, J. and Livage, Gelatin / silicate interactions : from nanoparticles to composite gels”. Colloids and Surfaces B: Biointerfaces, 35(2), 2004, 53-58.

[11] X. Yang, S.J.Liao, Z.X.Liang, Y.X. Li, L.Du, Gelatin-assisted templating route to synthesize sponge-like mesoporous silica with bimodal porosity and lysozyme adsorption behavior. Microporous and Mesoporous Materials, 143(2-3), 2011, $263-269$.

[12] J.Ge, J. Shi, L.Chen, Gelatin-based carbon microspheres with a foam-like core / solid shell structure. Carbon, 47(4), 2008, 11921195 .

[13] Chang, H. Y.Luo, C.Mou, H.Lin, Synthesis of gold nanoparticles containing mesoporous silica by using gelatin as template : CO oxidation reaction. Studies in Surface Science and Catalysis, 174, 2008, 297-300.

[14] S.H. Joo, S. Jun, and R.. Ryoo,Synthesis of ordered mesoporous carbon molecular sieves CMK-1". Microporous and Mesoporous Materials, 3( 44), 2001, 153-158.

[15] A.H. Lu, W.C. Li, W. Schmidt, and W. Kiefer, Easy synthesis of an ordered mesoporous carbon with a hexagonally packed tubular structure, Carbon, 42(14), 2004, 2939-2948.

[16] R. Guo, J.Guo, F.Yu, D. Dianchen, Microporous and Mesoporous Materials Synthesis and surface functional group modifications of ordered mesoporous carbons for resorcinol removal. Microporous and Mesoporous Materials, 175, 2013, $141-146$.

[17] P. Chys, and C.Gielens, 2011. FTIR 2D correlation spectroscopy of $\alpha 1$ and $\alpha 2$ fractions of an alkali-pretreated gelatin., BBA Proteins and Proteomics, 1814, 2011, 318-325.

[18] J. H. Muyonga, C.G.B .Cole, K.Doudu, Fourier transform infrared ( FTIR ) spectroscopic study of acid soluble collagen and gelatin from skins and bones of young and adult Nile perch ( Lates niloticus ), Food Chemistry 86, 2004.325-332.

[19] P.Valle-vigón, M. Sevilla, A.B.Fuertes, Carboxyl-functionalized mesoporous silica - carbon composites as highly efficient adsorbents in liquid phase, Microporous and Mesoporous Materials, 176, 2013, 78-85.

[20] R. K. Iler, The Chemistry of Silica: Solubility, Polymerization, Colloid and Surface Properties, and Biochemistry, (Wiley, New York, 1979)

[21] Y. N. Sazanov, A.V Gribanov, V. A Lysenko. The role of nitrogen atoms in forming the carbon structure in the carbonization of polymer composites.Journal of Fibre Chemistry, 40(4), 2008, 355-364.

[22] M.C. Moraes, De and R.L. Cunha, Gelation property and water holding capacity of heat-treated collagen at different temperature and $\mathrm{pH}$ values. FRIN, 50(1), 2013, 213-223.

[23] M.M. Horn, V.C.A.Martins, A.Maria, D. G. Plepis, Interaction of anionic collagen with chitosan: Effect on thermal and morphological characteristics. Carbohydrate Polymers, 77(2), 2009, 239-243.

[24] T. Lowell, and T.Shields, Characterization of Porous Materials and Powders: Surface Area, Pore Size and Density (Springer, 2004)

[25] S. J. Gregg, and K.S.W. Sing, Adsorption, Surface Area, and Porosity", 2nd edn, (Academic Press. 1982)

[26] P. Hudec, A. Smieskova, A. Zidek, B.B. Schneider, Determination of Microporous Structure of Zeolites by t-Plot Method - Stateof-the-Art. Studies in Surface Science and Catalysis, 23, 2002, 1587-1594. 